\title{
STUDI KATEGORISASI KONSERVASI PADA KOMPLEK SUSTERAN BANGKONG SEMARANG DARI PENDEKATAN DISIPLIN ARSITEKTUR
}

\author{
Sri Hartuti W *),Bambang Supriyadi, Sri Tudjono \\ *)Departemen Arsitektur, Fakultas Teknik, Universitas Diponegoro, \\ Jl. Prof. Soedarto, SH, Kampus Undip Tembalang, Semarang, Indonesia 50275
}

\begin{abstract}
Abstrak
Designing architecture development for Heritage Building should handled in carefully attention due to regulation has been protected the artefact. Most of development actions such as rehabilitation, renovation, redesign or development the individual building or building complex are related to develop the building into new function or other development in the context of extention of the needs. Conservation Catagorysation Study is one of the procedure can be used in which is provided through observation stage,documentation, catagorysation analysis to the heritage building complex as approach strategy before provide designing architecture developmentThis research just an example of guidline technique in the process of architectural design in developing heritage building complex based on preservationconservation strategies.Specific approach of architectural context will provide in the future continuing research from other discipline of approach such as archeologies approach to bring final conservation catagorysation comprehensively.
\end{abstract}

Keywords: categorization, conservation

\section{Pendahuluan \\ Sejarah}

Komplek bangunan Susteran Bangkong ini dimiliki Yayasan Katolik Marsudirini, dibangun sejak tahun 1910, dan secara bertahap dilanjutkan sampai sekitar tahun 1950-an. Semula digunakan sebagai Perkumpulan suster St. Fransiscus sebagai biara Katolik.

Tahun 1955, Sekolah Menengah Atas Sedes Sapientiae ditempatkan di Komplek Susteran Bangkong. Semula, SMA ini merupakan bagian dari SMA Loyola yang dirintis pendiriannya oleh Romo Waaweburg S.J. almarhum bersama Wiyono pada bulan Mei 1949. Memasuki tahun ajaran 1950/1951 diadakan pemisahan untuk siswa putra dan siswa putri. Siswa putri dipercayakan pengelolaannya pada suster-suster Fransiskanes dengan suster Suiberta sebagai wakil kepala sekolah.

SMA putri ini menempati gedung Kweekschool yang kemudian menjadi SPG St.Fransiskus Jl. Pemuda 159, yang sekarang menjadi SMIK St. Fransiskus. Pada tahun 1955, SMA Loyola putri dipindahkan ke Jl. Mataram 159 (Komplek Susteran Bangkong), dan mulai tahun itu diperkenalkan nama Sedes Sapientiae yang berarti "tahta kebijaksanaan" dan penge-lelolaannya diserahkan sepenuhnya pada komunitas Suster Fransiskanes.

Tahun 1981, SMP Maria Mediatrix, Akademi Sekretaris, Balai Pengobatan dan PIKAT bergabung di dalam komplek Bangkong. Tahun ajaran 1991-1992 ditambahkan bangunan berlantai 3 di sisi utara sebagai bangunan untuk perpustakaan, laboratorium dan ruang komputer $^{1}$

\section{Deskripsi Bangunan dan Ruang}

Komplek ini dirancang oleh arsitek H.J. Roosdorp. Tahun 1942-1945 pada masa pendudukan Jepang, sempat dijadikan tempat tahanan. Tahun-tahun pembangunan diawali pada 1910, selanjutnya tahun 1950-1951 ditambahkan bangunan sayap kanan dan kiri, tahun 1991 dilengkapi dengan bangunan 3 lantai di sisi utara komplek, setelah itu beberapa bangunan ditambahkan pada sisi timur, 2 dan 3 lantai.

\section{Masa bangunan}

Tata masa bangunan dirancang setangkup/simetri dengan pusat simetri adalah bangunan kapel. Disamping posisinya yang sentris, keutamaan sosok bangunan kapel ini diperkuat dengan hadirnya dua bentukan menara beratap piramida bersudut tajam, mengapit pintu masuk utama yang berlanggam gothic.

Bangunan pengapit membujur arah timur-barat dua lantai beratap limas terpancung di bagian ujungujungnya. Penambahan bangunan pada tahun -tahun 1991 makin melengkapi fasilitas yang diperlukan untuk kepentingan pendidikan.

\footnotetext{
1 Pemkot Semarang, Bappeda, SWB, 2006, Senarai
Bangunan Dan Kawasan Pusaka Budaya Kota

${ }^{1}$ Pemkot Semarang, Bappeda, SWB, 2006, Senarai
Bangunan Dan Kawasan Pusaka Budaya Kota Semarang, hal. A-10
} 


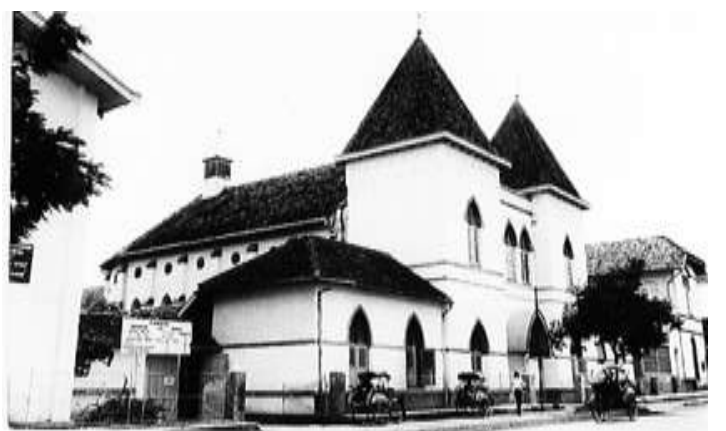

Gambar 2. Foto Bangunan Kapel Susteran Bangkong Semarang pada masa lalu (Sumber : Dokumentasi Jurusan Arsitektur FT Unika Soegijapranata)

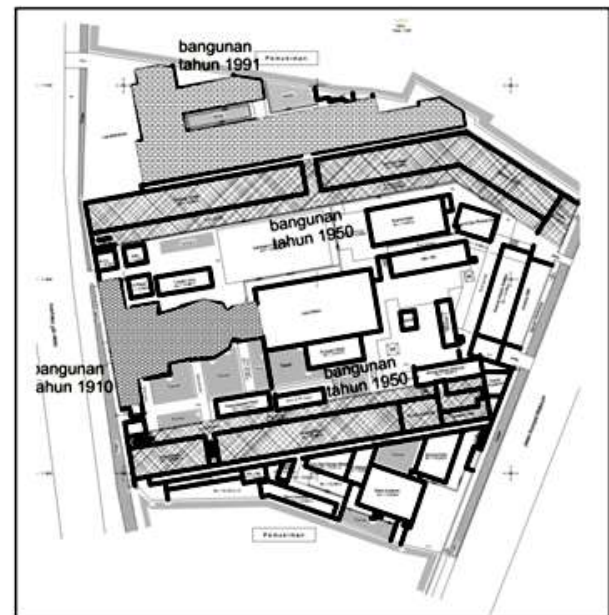

Gambar 3 : Perkembangan Masa Bangunan Susteran Bangkong Semarang (Sumber : Pemkot Semarang Bappeda,SWB 2006)

\section{Struktur dan Konstruksi}

Bangunan-bangunan lama (tahun 19101950-an), menggunakan jenis pondasi lajur batu belah, sementara bangunan baru (1991-an) menggunakan jenis pondasi beton setempat pada kolom-kolom bangunan, dan untuk dinding menggunakan jenis pondasi lajur batu belah.

Dinding menggunakan batu bata, setebal 1.5 batu $(50 \mathrm{~cm})$ untuk bangunan lama, sementara, untuk bangunan baru ketebalan dinding $15 \mathrm{~cm}$.

Sistem struktur pada bangunan lama adalah "konstruksi dinding pemikul (bearing wall)" dengan penebalan dinding sampai 2 batu $(70 \mathrm{~cm})$ pada sudut dan tempat-tempat tertentu. Untuk bangunan baru menggunakan sistem rangka beton bertulang.

Konstruksi lantai atas (bangunan 2 lantai) untuk bangunan lama menggunakan baja profil IWF yang bersilangan tegak lurus dan beton tak bertulang berpenampang lengkung-lengkung sekaligus menjadi ceiling bagi ruangan di bawahnya. Untuk ba-ngunan baru menggunakan konstruksi balok dan pelat beton bertulang sebagaimana kelaziman saat ini.

Selasar pada bangunan lama meng-gunakan pipapipa besi dengan cornice sebagai konstruksi pemikul lantai dan atap.

Konstruksi atap adalah kuda-kuda kayu dengan penutup genting. Khusus untuk bangunan kapel konstruksi atap meng-gunakan besi dengan bentuk lengkung di bagian dalam yang kemudian memungkinkan dibuat ceiling lengkung berbahan kayu.

\section{Idiom Arsitektural dan Detail}

Secara umum meski tidak sepenuh-nya, pada bangunan-bangunan lama nampak pengaruh Arsitektur Gothic menjadi inspirasi pengolahan idiom arsitekturalnya.

- Lantai bangunan menggunakan tegel pc abu-abu dengan permukaan rata untuk ruang dalam, dan tegel PC bertekstur (tegel badak) untuk selasar. Lantai berwarna dengan motif beralur, banyak digunakan pada bagian tengah ruang.

- Lantai bermotif ini masih dalam kondisi baik, kerusakan dan kekusaman lebih banyak dijumpai di bagian selasar (border lantai).

- Dinding bata seluruhnya di cat. Penge-catan ulang yang dilakukan menggunakan bahan cat dinding emulsi akrilik.

- Pelubangan untuk pintu-jendela sebagian besar berbentuk lengkung gothic yang dicirikan dengan busur meruncing (dengan satu titik puncak), termasuk idiom pelisir di atas jendela.

- Semula, jendela-jendela di bangunan kapel yang berbentuk busur atau lengkung gothic diisi dengan kaca bening dibingkai dengan list-list persegi. Saat ini jendela tersebut telah diganti dengan kaca patri berwarna (glass in lood) dan bermotif (tahun pemasangannya tidak dike-tahui).

\section{Dasar-dasar Pertimbangan}

Ibarat sebuah buku, kota dengan ruang dan bangunan-bangunannya adalah lembaran-lembaran tertulis yang selayaknya dapat dibaca secara lengkap sebagai suatu narasi kesejarahan. Lembar-lembar ini terus bertambah seiring dengan bertambahnya waktu. Lapis-lapis perkembangan kota terwakili oleh hadirnya bangunan-bangunan, yang kemudian menjadi bagian penting dalam memberikan karakteristik tertentu.pada bagian-bagian ruang kota, bahkan selanjutnya karakteristik kota secara keseluruhan.

Bangunan lama adalah kekayaan khasanah kesejarahan kota. Kelestarian bangunan-bangunan lama menjadi bukti fisik dan visual yang sepatutnya tetap terjaga agar identitas kota dapat tetap terpelihara. Tanpa 
identitas, sesuatu (dalam hal ini kota) akan teralinasi kehadirannya.

Tidak dapat dipungkiri bahwa bangunanbangunan lama yang ada di perkotaan Indonesia pada umumnya, saat ini sebagian besar dalam kondisi yang kurang baik dari sisi fisik dan visualnya. Penggunaan bangunan sering mengabaikan kaidah dan persyaratan preservsi-konservasi yang benar.

Kesadaran terhadap nilai-nilai yang melekat pada bangunan lama acapkali terpinggirkan, yang kemudian menyebabkan munculnya perlakuan-perlakuan yang tidak semestinya, seperti pembongkaran, pengubahan, serta penambahan-penambahan bagian ba-ngunan atau pun penambahan bangunan-bangunan baru yang tidak tepat.

Pertimbangan nilai ekonomis sering menjadi penyebab pertama datangnya ancaman terhadap kelestarian bangunan lama. Bangunan lama biasanya terletak di pusat kota (lama) dan sering menjadi pusat aktivitas ekonomi, politik, sosial dan budaya kota, sehingga memiliki keunggulan nilai lokasi yang relatif tinggi strategis. Oleh karena nilai lokasi yang tinggi secara ekonomis maka kemudian muncul pan-dangan bahwa penggunaan tanah di lokasi semacam ini harus optimal. Bangunan diupayakan memiliki luas lantai yang besar. Sementara itu, bangunan-banguan lama umumnya hanya berlantai satu atau dua dengan ruang dalam yang relatif sempit (untuk ukuran kebutuhan ruang saat ini)

Hal kedua, pertimbangan fungsional sering menjadi penyebab berikutnya. Ruangan yang sempit, luasan ruang terbatas serta tampilan yang masif/pejal, biasanya dinilai tidak sesuai dengan kebutuhan fungsifungsi baru saat ini.

Ketiga, tampilan fisik dan konstruksi dari bangunan lama kebanyakan dalam kondisi yang kurang baik, yang disebabkan oleh usia ba-ngunan, perawatan yang kurang tepat, pengaruh eksternal seperti polusi, banjir, gempa dan vandalisme atau penggunaan bangunan yang kurang sesuai, serta intensitas kegiatan yang berlebihan.

Mengingat arti penting bangunan-bangunan lama bagi sebuah kota serta ancaman-ancaman kelestariannya maka beberapa dasar pertim-bangan dapat dirangkum sebagai berikut :

a. Tindakan preservasi dan konservasi ter-hadap bangunan lama sebaiknya dilakukan untuk menjaga kelestarian kesejarahan kota. Bangunan lama sebagai artifak fisik dan visual sebagai salah satu unsur yang berperan menciptakan karak-teristik dan identitas kota $\mathrm{n}$ tetap terjaga eksistensinya

b. Penipisan ancaman kelestarian dari aspek ekonomi, fungsional, fisikal dan kons-truksi, mengisyaratkan bahwa preservasi dan konservasi sepatutnya secara terkendali mengarah pada konservasi yang bersifat dinamis, yang dapat diartikan bahwa untuk bangunan-bangunan tertentu dimungkinkan ada-nya alih fungsi, renovasi bahkan pe-ngembangan yang patut, tanpa mengurangi integritas kandungan nilainilai yang dimiliki.

\section{Kajian Teori}

Acuan Undang-undang, Peraturan, Teori dan Kaidah Konservasi

Sebagai landasan indakan preservasi-konservasi dan pengembangan, beberapa peraturan dan perundangundangan dapat disebutkan disini, antara lain :

Benda Cagar Budaya (BCB) sesuai dengan Undang Undang Republik Indonesia No. 5 Tentang Benda Cagar Budaya Tahun 1992 :

a. Benda buatan manusia ; bergerak, tak bergerak, kesatuan (kelompok), umur sekurang-kurangnya 50 tahun, mewakili gaya sekurang-kurangnya 50 tahun, mempunyai nilai penting bagi sejarah, ilmu pengetahuan dan kebudayaan.

b. Benda Alam ; mempunyai nilai sejarah, ilmu pengetahuan kebudayaan.

c. Situs (site); lokasi yang mengandung BCB lokasi yang diduga mengandung $\mathrm{BCB}$, lingkungan yang diperlukan pengamanannya.

Kutipan Pasal 19 (UURI N0.5, tahun 1992)

Benda cagar budaya tertentu dapat diman-faatkan untuk kepentingan agama, sosial, pariwisata, pendidikan, ilmu pengetahuan dan kebudayaan.

Pemanfaatan sebagaimana dimaksud dalam ayat (1) tidak dapat dilakukan dengan cara atau apabila bertentangan dengan upaya perlindungan benda cagar budaya sebagaimana dalam pasal 15 ayat (2) yaitu :।

(1) Setiap orang dilarang merusak benda cagar budaya dan situs;

(2) Tanpa izin dari pemerintah setiap orang dilarang : a. Membawa $\mathrm{BCBb}$ ke luar wilayah RI, b. Memindahkan BCB dari daerah satu ke daerah lain, c. Mengambil atau memindahkan BCB baik sebagian maupun selu-ruhnya, kecuali dalam keadaan darurat, d. Mengubah bentuk dan/ atau warna serta memugar BCB, e. Memisahkan sebagian BCB dari kesatuannya, f. Memperdagangkan atau memperjualbelikan atau memper-niagakan BCB.

(3) Pelaksanaan ketentuan dan perizinan sebagaimana dimaksud dalam ayat (2) ditetapkan dengan Peraturan Pemerintah semata-mata untuk mencari keuntungan pribadi dan/atau golongan.

Ketentuan tentang benda cagar budaya yang dapat dimanfaatkan untuk kepentingan seba-gaimana dimaksud dalam ayat (1) dan cara pemanfaatannya ditetapkan dengan Peraturan Pemerintah. 
Kutipan Pasal 20-23 (UURI N0.5, tahun 1992)

- Pasal 20, Pemerintah dapat menghentikan pemanfaatan $\mathrm{BCB}$ apabila pelaksanaannya ternyata berlangsung sebagaimana dimaksud dalam pasal 19 ayat (2).

- Pasal 21, BCB yang pada saat ditemukan ternyata sudah tidak dimanfaatkan lagi seperti fungsi semula dilarang untuk dimanfaatkan lagi.

- Pasal 22, BCB bergerak atau BCB tertentu baik yang dimiliki oleh negara maupun perorangan dapat disimpan dan/ atau dirawat di museum. Pemiliharaan BCB yang disimpan atau dirawat di museum sebagaimana dimaksud dalam ayat (1) ditetapkan dengan Peraturan Pemerintah.

- Pasal 23, Pemanfaatan BCB dengan cara penggandaan wajib mendapatkan ijin dari pemerintah. Ketentuan mengenai pemberian izin sebagaimana dimaksud dalam ayat (1) ditetapkan dengan peraturan pemerintah.

\section{Implementasi Kaidah Konservasi}

Bertolak dari Undang-undang tentang Benda Cagar Budaya Republik Indonesia No 5 tahun 1992 di atas, dan berbagai dasar pertimbangan yang telah dikemukakan, maka rangkuman dalam upaya preservasi dan konservasi dapat dijelaskan, sebagai berikut :

\section{Tujuan Preservasi dan Konservasi :}

Preservasi dan konservasi ditujukan agar bangunan (benda cagar budaya) dapat dipelihara dan dilestarikan untuk tetap menjaga identitas dan gambaran masa lalu (nilai kesejarahan)

Beberapa acuan yang dapat dipandang sebagai kaidah preservasi-konservasi dan pengem-bangan, antara lain adalah sebagai berikut :

a. Preservasi adalah kegiatan perawatan benda cagar budaya yang dilakukan dengan cara menanggulangi pengaruh faktor internal dan ekternal yang dapat mengancam kelestarian bangunan cagar budaya.

b. Konservasi adalah kegiatan pemeliharaan yang dilakukan terhadap benda cagar budaya yang telah mengalami kerusakan atau penurunan kualitasnya.

c. Pengembangan adalah tindakan optimalisasi benda cagar budaya dengan cara penambahan, perluasan dan pembangunan baru tanpa mengganggu bahkan kehadirannya dapat memperkuat eksistensi benda cagar budaya. Pengembangan seharusnya tetap menjaga orisinalitas dan otentisitas baik dalam hal bahan, rancangan, idiom, kekriyaan dan tempat (setting)

\section{Prinsip Dasar Preservasi-Konservasi}

a. Dokumentasi

Sebelum kegiatan fisik preservasi-konservasi dilakukan, penelitian terhadap bangunan lama seharusnya dilakukan dengan cermat. Dokumentasi menjadi bagian penting pada awal upaya. Hal ini tidak hanya sebagai landasan tindakan preservasi-konservasi yang akan dilakukan, tetapi sebagai bagian dari pengarsipan data-data bangunan.

Langkah dokumentasi, akan menyangkut :

Data Kesejarahan :

a.Nama bangunan (semula, perkembangan dan saat ini)

b.Lokasi (jalan, kota, propinsi\}

c.Fungsi/kegunaan (semula, pengubahan fungsi, dan saat ini)

d.Waktu-waktu pembangunan

e.Perancang, pemrakarsa dan sebagainya

f. Catatan perubahan atau penambahan bagian bangunan

g.Nara sumber

Data Survai Visual (penggambaran, pemo-tretan, pencatatan):

a.Elemen Bangunan (Pondasi, dinding, kolom, atap dan detail)

b.Sistem struktur dan jenis konstruksi

c. Bentuk dan detail bangunan

d.Ornamentasi

e. Kelengkapan Interior, elemen dekoratif

Setting :

a. Integritas tapak dan bangunan

b. Bangunan sekitar atau bangunan yang berkaitan

c. Ruang luar

Kondisi:

a. Kondisi fisik saat ini

b. Pencatatan kerusakan dan penurunan kualitas baik secara internal maupun eksternal

(Burns, John (ed), 1989p31)

b.Tahap Kegiatan Preservasi-konservasi

Kegiatan preservasi dan konservasi dapat dilakukan secara bertahap, sampai batas tahap yang sesuai atau selayaknya dapat dipenuhi, yakni :

1. Pemeliharaan karakter penting

Merupakan upaya untuk melestarikan bangunan lama, antara lain kekayaan bagian atau elemen bangunan dan ornamentasi harus tetap terjaga, unsur eksterior dan interior tertentu harus tetap telindungi eksistensinya, walaupun jika terjadi alih fungsi. Perubahan atupun penambahan seiring dengan berjalan-nya waktu, selayaknya dihargai selama perubahan atau penambahan ini tidak mengurangi kualitas esetika, dan teknisnya.

2. Pencegahan degradasi kualitas

Perawatan dan pengawasan dilakukan secara teliti termasuk didalamnya perbaikan unsur atau elemen bangunan.

3. Penguatan bangunan 
Dilakukan untuk memperkokoh bangunan atau bagian-bagiannya agar lebih awet. Bilamana penguatan secara orisinal tak dapat lagi diterapkan,maka teknologi baru dapat digunakan, dengan catatan kesatuan sistem struktur dan bukti-bukti sejarah tidak boleh hilang atau dimusnahkan.

4. Pemulihan atau pembaruan

Merupakan pekerjaan yang perlu mendapatkan perhatian seksama karena tidak hanya berhubungan dengan artifak fisik tetapi juga menyangkut penggalian sumber informasi yang akurat agar restorasi dapat dilakukan tanpa adanya penyimpangan yang berlebihan. Penyelamatan dengan cara restorasi secara struktural dapat dilakukan dengan hati-hati agar tidak merusak sistem struktur dan konstruksi semula.

5. Rehabilitasi atau perbaikan

Adalah proses pengembalian properti pada satu kesatuan,melalui perbaikan atau perubahan sehinga kegunaannya dapat lebih optimal. Salah satu cara memlihara yang cukup efektif adalah merehabilitasi kegunaannya secara aktif selama kesatuan struktur, arsitektur dan kualitas ruangnyatetap terpelihara.

6. Reproduksi atau peniruan

Adalah upaya yang dapat ditempuh untuk memperbaiki bagian-bagian bangunan yang rusak atau hilang, namun pada bagian-bagian tertentu yang tidak merupakan satu kesatuan bagian bangunan, maka peniruan atau reproduksi harus secara jujur menampakkan adanya peniruan baru yang dilakukan.

7. Pembangunan kembali atau rekonstruksi

Adalah upaya untuk menghadirkan kembali bagian atau keseluruhan bangunan sebagaimana semula. Langkah ini ditempuh bilamana kondisi bangunan pada saat ini telah mengalami penurunan kualitas secara signifikan, atau perubahan yang cukup drastis sehingga kesatuan integritas bangunan menjadi hilang atau menurun.

c. Beberapa Aturan Pelaksanaan Preservasi-konservasi

1. Bangunan

Disarankan: Penekanan pada bentuk dasar dan kesatuan struktur. Mengenali kemungkinan masalah yang timbul dalam sistem struktur bangunan seperti tanda keretakan, penggetaran, penyimpangan atau kegagalan. Kemampuan memantapkan dan memperbaiki kelemahan struktur dan konstruksi

Dihindarkan : Mengganggu keberadaan pondasi lama dengan penggalian atau kegiatan fisik lainya yang mungkin akan merusak stabilitas sehingga memperpendek usia bangunan.

\section{Eksterior}

Disarankan : Mengutamakan pada pembuatan dinding sebagaimanan aslinya. Memperbaiki lapisan/plesteran yang umumnya memiliki persoalan kelembaban. Memperbaiki atau menggganti material yang sudah rusak dengan material baru yang sejenis atau mirip. Merehabilitasi elemen-elemen aristektural yang telah rusak atau hilang.

Dihindarkan: Penambahan bahan-bahan baru yang tidak sesuai untuk bangunan lama. Memindahkan, memotong, atau memodifikasi elemen bangunan lama yang diduga akan merusak orisinalitas dan karakteristik bangunan lama.

3. Interior

Disarankan : Penekanan pada material asli untuk elemen arsitektural. Memperbaiki atau mengganti material yang rusak dengan material baru yang sama atau mirip dengan aslinya. Menjaga keaslian kelengkapan perabotan interior.

Dihindarkan :Memindahlkan elemen interior yang penting. Mengganti ornamentasi lama dengan moderl dan bahan baru. Menambahkan elemen interior yang mengganggu eksistensi interior lama. Menambahkan perabotan yang kurang sesuai.

4. Konstruksi

Disarankan : Menambahkan dengan tujuan memperkuat struktur lama. Melindungi kekayaan arsitektural dan konstruksi.

Dihindarkan : Penambahan struktur atau konstruksi yang tidak dapat bersenyawa dengan struktur/konstruksi lama. Menbambah ketinggian baru pada bangunan lama seperti mengubah sudut atap, mempertinggi/meninggikan peil plafond ( ceiling) yang akan merusak / menganggu karakter bangunan.

\section{Data Komplek Susteran Bangkong}

Penjabaran Data Komplek Susteran Bangkong dapat dilihat pada rincian visualisasi berikut ini : 


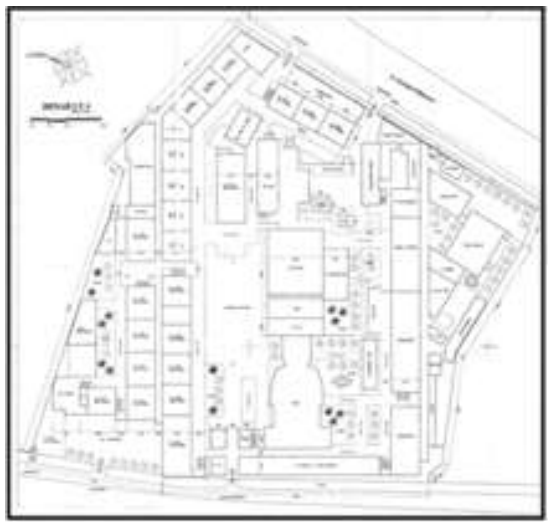

Denah Lantai 1

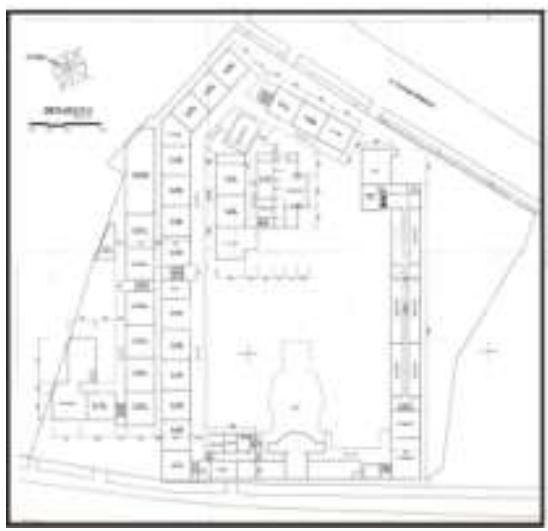

Denah Lantai 2

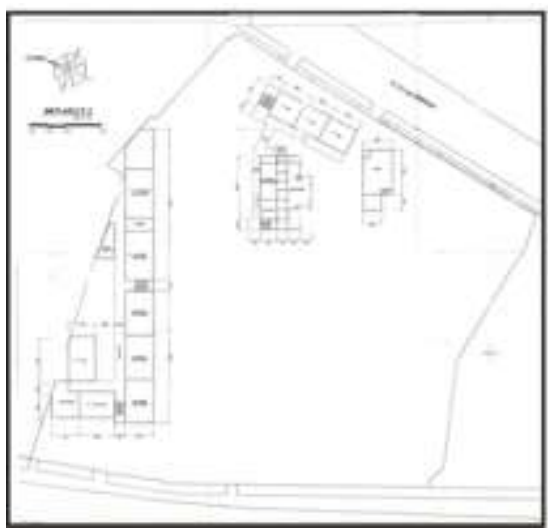

Denah Lantai 3

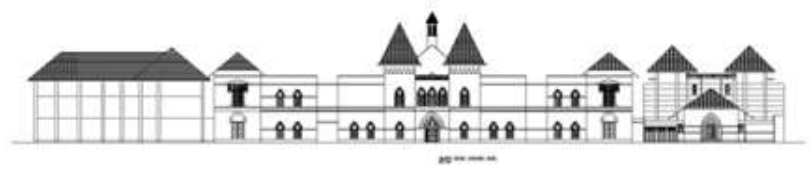

\author{
Gambar 4. Denah , Tampak Depan Komplek \\ Susteran Bangkong \\ (Sumber : Dokumentasi Peneliti)
}
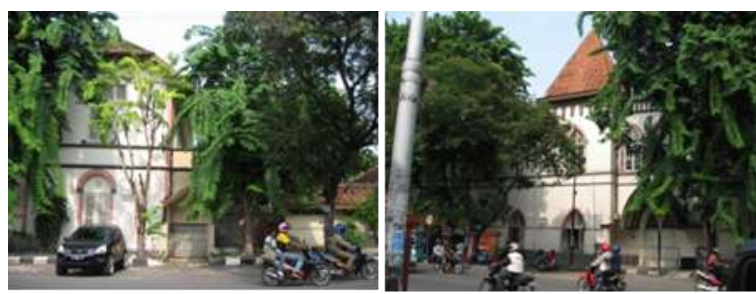

Blok Bangunan Kelas (bangunan kuno 1950 dan bangunan kelas tambahan 2 dan

3 lantai), lapangan basket

membujur ke arah barat-timur

sehingga tidak sesuai standar

teknis sarana olah raga

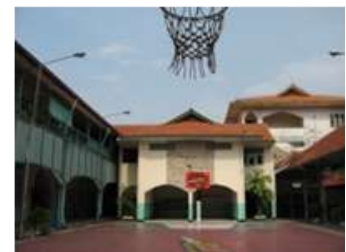

Gambar 6. Foto Komplek Susteran Bangkong Sumber : Dokumentasi Peneliti

\section{Unit Bangunan Kapel}

Merupakan bangunan utama dalam komplek Susteran Bangkong, selain fungsinya penem-patannya juga menunjukkan posisi utama yaitu diapit oleh deretan blok bangunan kelas dan bangunan kapel tersebut berada di sisi depan yang berhubungan langsung dengan Jl. MT Haryono. Dibangun pada tahun 1910 dan merupakan pembangunan paling awal dalam komplek tersebut.

Mempunyai karakter khusus berkaitan dengan bentuk dan tampilan bangunannya yaitu bercirikan arsitektur gothic dengan deretan jendela pada samping bangunan dengan bentuk jendela runcing. Penegasan karakter Kapel semakin jelas karena bentuk atap dan dilengkapinya menara kecil pada bagian atas altar.

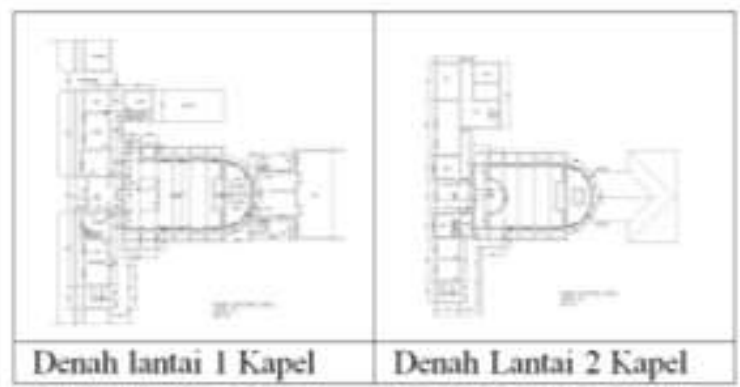

Gambar 7. Denah Bangunan Kapel

(Sumber : Dokumentasi Peneliti) 


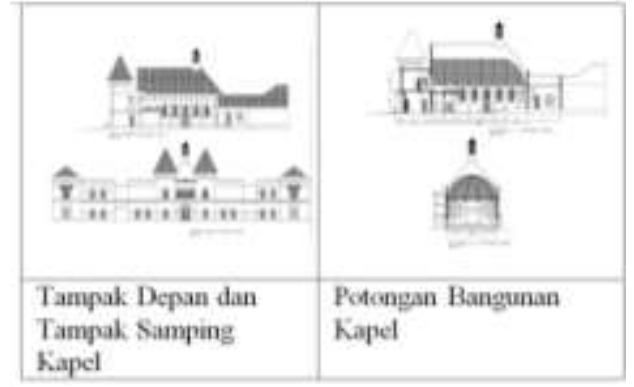

Gambar 8. Tampak dan Potongan Bangunan Kapel (Sumber : Dokumentasi Peneliti)

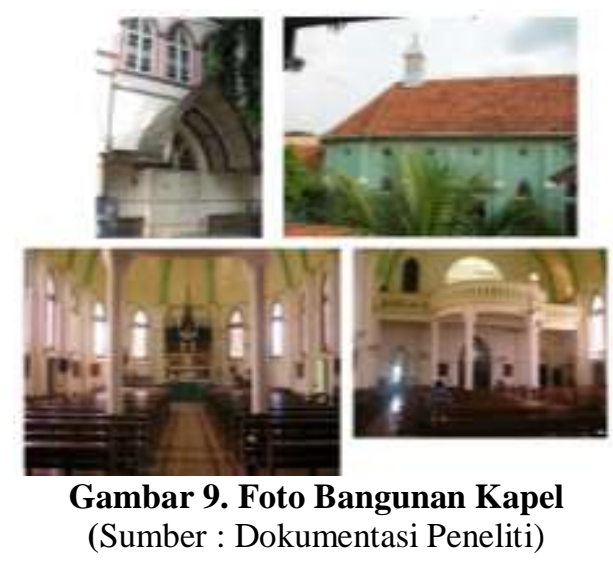

Unit Bangunan Kelas

Terdapat 2 unit sekolah dalam komplek Susteran Bangkong yaitu SMP Maria Mediatrix dan SMA Sedes Sapientiae, pengelolaan kegiatan belajar mengajar dilakukan secara terpisah dengan selain organisasi juga bangunan kelas secara signifikan menempati blok massa yang terpisah yaitu mengapit lapangan olah raga , aula dan kapel.

Dari tampilan bangunan yang terdokumentasi terlihat bahwa sebagian merupakan unit bangunan baru yaitu yang penempatannya mengisi ruang antara dua blok bangunan kelas yang eksisting, serta berada di sisi belakang yang berdekatan dengan jalan Kompol Maksum.

Bangunan Kelas sebagian dibangun pada tahun 1950-an (meskipun sebelumnya bukan untuk kelas semua) yaitu dengan ciri utama pola deretan ruang dengan selasar di bagian depan, tampilan arsitektur dengan bentuk atap limasan dan serambi dengan atap pelana, detail arsitektural secara signifikan tampil pada komponen pintu, jendela, pengolahan kolom dan penutup selasar. Penggunaan material secara spesifik masih tampil yaitu berupa jenis ubin PC (warna dan tekstur)

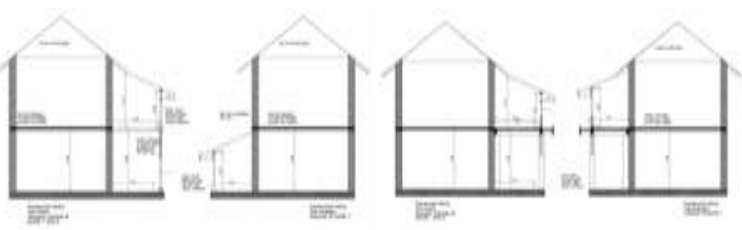

Gambar 10. Tipikal Potongan Bangunan Kelas(1950) Sumber : Dokumentasi Peneliti

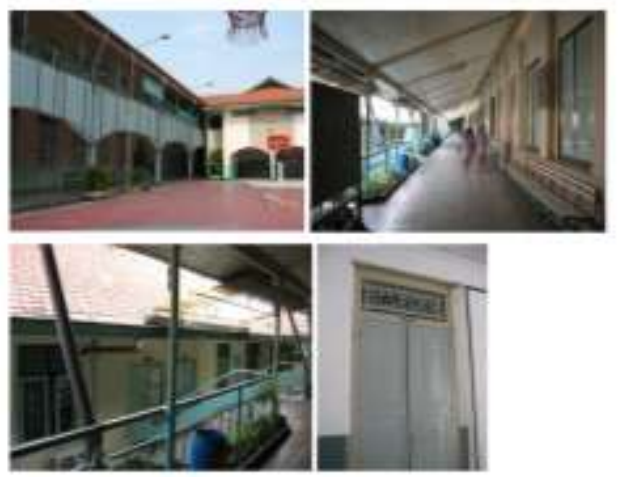

Gambar 11. Foto-foto Bangunan Kelas (1950 dan 1990) Sumber : Dokumentasi Peneliti

\section{Unit Bangunan Susteran (Biara)}

Blok Bangunan Susteran terletak di sudut Komplek Susteran Bangkong, pada saat survai dilakukan telah dilakukan renovasi (2008) terhadap blok tersebut yaitu meliputi : pekerjaan penambahan ruang tidur ( jumlah lantai secara vertikal bertambah) dan penyelesaian tampak bangunan akibat penambahan jumlah ruang. Secara prinsip renovasi yang dilakukan sifatnya mengoptimalkan lahan yang tersedia semula dengan pembangunan ke arah atas untuk pemenuhan kebutuhan ruang yang berkembang. Serta penegasan zona area sekolah dengan susteran, sehingga sebagian bagian depan bangunan susteran yang lama dioptimalkan untuk bangunan kelas SMP Maria Mediatrix. 

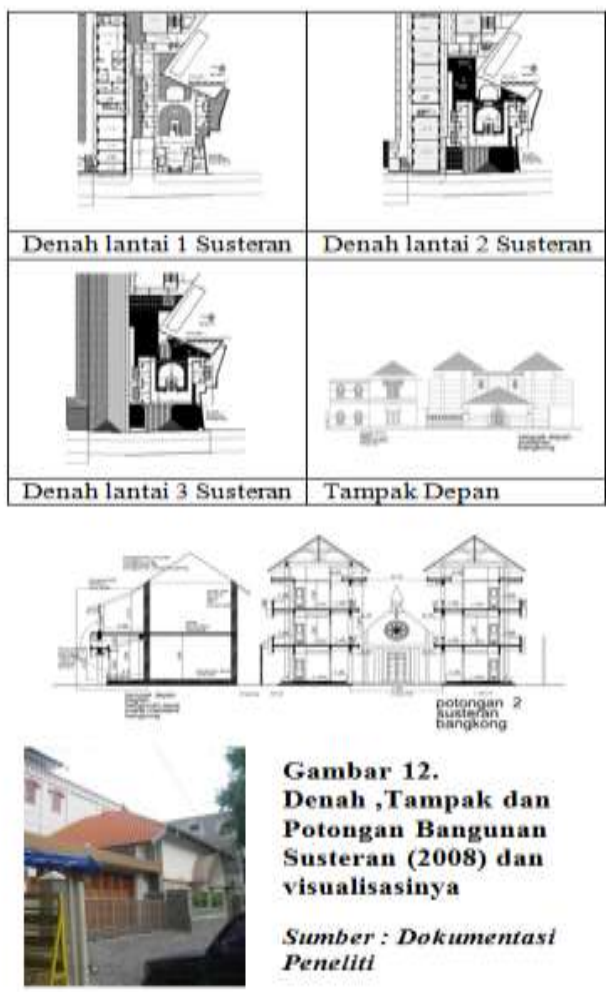

Gambar 12 .

Denah, Tampak dan

Potongan Bangunan Susteran (2008) dan visualisasinya

Sumber : Dokumentasi Peneliti

\section{Analisis Kategorisasi \\ Analisis Ruang dan Bangunan}

Secara keseluruhan, Komplek Susteran Bangkong ini terdiri dari beberapa gugus masa dan fungsi bangunan, yakni :

Kelompok Kapel, beserta kelengkapan ruangruang penunjang, terletak di tengah depan sebelah barat. Kelompok SMA Sedes Sapientiae dan SMP Maria Mediatrix menempati sisi utara terdiri dari beberapa gugus bangunan (lama dan baru). Kelompok susteran dan PIKAT berada di sisi selatan, terdiri dari beberapa gugus bangunan (lama dan baru).

Kebutuhan ruang untuk kegiatan belajarmengajar yang meningkat beberapa tahun terakhir, menyebabkan hadirnya bangunan-bangunan tambahan, terutama di sisi timur, yang sebagian besar untuk tambahan ruang SMP Maria Mediatrix. . Secara fungsional, tambahan bangunan ini cukup banyak memenuhi kebutuhan ruang, namun karena pembangunannya sangat bersifat pragmatis, sementara lahan relatif terbatas, menyebabkan terjadinya penurunan kesatuan ruang dan bangunan secara keseluruhan. Beberapa penyebabnya adalah antara lain, pada tampilan bangunan baru yang bermacam-macam dan tidak bersenyawa dengan tampilan bangunan lama.

\section{Analisis Figure-ground}

Analisis ini dilakukan guna memperjelas kondisi aktual ruang dan bangunan objek penelitian. Dalam analisis secara grafis, beberapa catatan dapat diketengahkan, sebagai berikut :

a. Kepadatan bangunan nampak meningkat dengan hadirnya bangunan-bangunan baru, terutama di sisi sebelah timur

b. Ruang-ruang antar bangunan dibeberapa tempat nampak sempit yang menyebabkan munculnya ruang-ruang atau lorong yang gelap

c. Ruang luar antar bangunan kurang jelas orientasinya dan nampak rancu

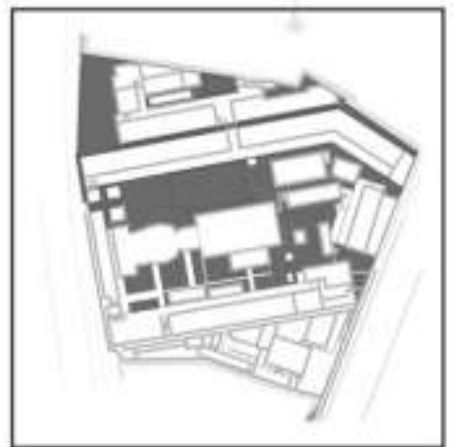

Gambar 16.Analisis Figure-Ground -1: identifikasi pola penempatan massa bangunan (deretan bangunan dan orientasi) Sumber: Analisis Peneliti

\section{Analisis Struktur dan Konstruksi}

Secara umum konstruksi bangunan lama masih menampakkan kekokohan, terutama pada kelompok kapel dan kelompok bangunan susteran di sisi selatan. Halini ditandai dengan tidak dijumpainya indikasi kerusakan struktural, seperti retak dinding, penurunan dinding/ bangunan, retakan lantai dasar, taupun deformasi atap.

Kekhawatiran terjadinya kerusakan terjadi pada bagian selasar dan lantai ruang-ruang di lantai atas yang digunakan untuk kelas. Hal ini diindikasi oleh terjadinya getaran yang cukup besar pada saat digunakan. Penyebab terjadinya ancaman kerusakan dapat dimaklumi mengingat selama lebih dari 50 tahun, bangunan ini secara intensif digunakan untuk aktifitas siswa yang semakin lama semakin meningkat jumlahnya, yang tentu melebihi kapasitas yang semula tidak terduga. Konstruksi baja profil dengan beton tak bertulang seperti yang ada, tentu memiliki keterbatasan beban yang harus dipikul. Lendutan dan kelelahan bahan menjadi wajar terjadi.

\section{Analisis Arsitektural}

Secara arsitektural Komplek Susteran Bangkong tidak mengalami perubahan yang cukup besar terutama disisi utama atau facade depan yang menghadap Jl. MT Haryono. Sisi timur adalah sisi yang paling berubah oleh bangunan-bangunan baru (R. Kelas dan Lab). 
Khusus untuk facade depan (timur) perubahan terjadi dengan adanya penambahan lantai bangunan menjadi dua lantai di sebelah menara kembar. Sayangnya penambahan ini saat ini kurang difungsikan secara optimal, dan secara arsitektural kurang sesuai, lebih-lebih dengan ditempatkannya 'jendela' palsu di bagian atas yang menurunkan kualitas arsitekturalnya serta kesatuan tampilan facade.

\section{Analisis Kategorisasi}

Analisis kategorisasi yang dilakukan terhadap obyek bangunan yang diteliti adalah dengan mengkaji kesesuaian kondisi eksisting dengan kategorisasi implementasi Preservasi - Konservasi yang akan diterapkan berdasar data kesejarahan, data visual survai, setting (posisi) dan kondisi masing-masing blok bangunan yang ada dalam Komplek Susteran Bangkong. Adapun hasilnya sebagai berikut :

Tabel 1. Hasil Analisis Kategorisasi

\begin{tabular}{|c|c|c|}
\hline No. & Bangunan & Arahan Tindakan \\
\hline 1. & $\begin{array}{l}\text { Bangunan Kapel } \\
\text { (preservasi- } \\
\text { konservasi) }\end{array}$ & $\begin{array}{l}\text { Pemeliharaan karakter } \\
\text { penting, pencegahan } \\
\text { degradasi kualitas dan } \\
\text { penguatan konstruksi }\end{array}$ \\
\hline \multirow[t]{3}{*}{2.} & $\begin{array}{l}\text { Bangunan Kelas } \\
\text { (Sekolah) }\end{array}$ & $\begin{array}{l}\text { Unit bangunan lama } \\
(\mathbf{1 9 5 0 )} \text { : pemeliharaan } \\
\text { karakter penting, } \\
\text { pencegahan degradasi } \\
\text { kualitas, penguatan } \\
\text { konstruksi dan rehabilitasi }\end{array}$ \\
\hline & & $\begin{array}{l}\text { Unit bangunan baru } \\
\text { (1990) : rehabilitasi untuk } \\
\text { yang penyesuaian } \\
\text { integrasi, bahkan } \\
\text { bilamana diperlukan } \\
\text { dilakukan demolisi karena } \\
\text { untuk efektifitas lahan } \\
\text { tapak dan dibangun } \\
\text { kembali sesuai arahan } \\
\text { penyelesaian konfigurasi } \\
\text { massa bangunan }\end{array}$ \\
\hline & & $\begin{array}{l}\text { Unit bangunan } \\
\text { penunjang (Aula \& } \\
\text { Sarana OR) } \\
\text { :penyesuaian standar } \\
\text { teknis dan tata massa } \\
\text { bangunan (demolisi) dan } \\
\text { pemindahan posisi. }\end{array}$ \\
\hline 3. & $\begin{array}{l}\text { Bangunan } \\
\text { Susteran (Biara) }\end{array}$ & $\begin{array}{l}\text { Merupakan hasil renovasi } \\
\text { 2008, untuk sementara } \\
\text { dapat dipertahankan } \\
\text { (posisi dan tampilannya) } \\
\text { telah mengikuti kaidah } \\
\text { teknis maupun konservasi }\end{array}$ \\
\hline
\end{tabular}

\section{preservasi yang berlaku.}

Sumber: Analisis Peneliti

\section{Kesimpulan dan Rekomendasi \\ Kesimpulan}

Dari hasil kajian aktual Komplek Susteran Bangkong Semarang sesuai lingkup penelitian, analisis dan beberapa catatan implementasi, dapat dikemukakan beberapa kesimpulan sebagai berikut :

a. Komplek Susteran Bangkong merupakan salah satu BCB yang ditetapkan atas dasar latar belakang kesejarahannya, mewakili arsitektur pada jamannya

b. Untuk itu Yayasan Marsudirini selaku pengelola telah memulai upaya kegiatan konservasi-pereservasi dengan dimulainya pembangunan secara signifikan yaitu reno-vasi Susteran (Biara) pada tahun 2008.

c. Bangunan Utama (Kapel) perlu mendapat perhatian mengingat karakter yang harus dipertahankan namun perlu penanganan secara serius terhadap permasalahan peil lantai yang harus diolah akibat naiknya peil jalan dan saluran di masa kini.

d. Penguatan struktur bangunan merupakan tindakan yang sangat penting mengingat intensitas penggunaan bangunan yang tinggi serta digunakan oleh banyak orang (fungsi pendidikan)

e. Langkah konservasi secara dinamis sepatutnya menjadi landasan orientasi (mengikuti perkembangan jaman dan kebutuhan tanpa meninggalkan kaidah pelestarian yang seharusnya).

f. Pembangunan pada saat sekarang yang dilakukan ( bangunan aula, menara dan lapangan olah raga) secara visual sudah menempati area yang sifatnya tidak mengganggu karakter utama komplek, namun kajian untuk tampilan bangunannya belum dilakukan mengingat keterbatasan waktu penelitian (kegiatan pembangunan sedang mulai berlangsung saat survai penelitian dilakukan).

\section{Rekomendasi}

Beberapa rekomendasi dapat disajikan sebagai hasil akhir penelitian, atara lain :

a. Organisasi kelompok kegiatan :

Kapel sebagai fasilitas ibadah dan menjadi titik sentral komplek dipertahankan fungsinya. Bangunan sayap utara yang terdiri dari bangunan lama 2 lantai dan bangunan baru 3 lantai difungsikan hanya khusus untuk kegiatan Blok SMA Sedes Sapientiae.

Bangunan Memanjang di sayap selatan digunakan untuk Blok SMP Maria Mediatrix, sehingga secara simetri bangunan kapel menjadi pusat orientasi kegiatan pendidikan.

Kelompok Bangunan Susteran sudah menem-pati area di sisi selatan dan sedikit terpisah dari konfigurasi utama (pemisahan kelompok kegiatan pendidikan dan biara). 
b. Arsitektural :

Secara arsitektural, upaya preservasi-konservasi dan pengembangan diorientasikan untuk memperkuat eksistensi integritas bangunan lama. Beberapa di antaranya yang cukup signifikan adalah wajah depan (facade) Kapel yang sebaiknya dikembalikan pada bentuk semula yakni bangunan satu latai beratap limas. Hal ini mengingat pada aspek fungsional yang kurang diperlukan serta tampilan arsitektural-nya kurang tepat.

Tampilan bangunan baru yang dimungkinkan ditambahkan ( aula, menara, atau lainnya ) sebaiknya menggunakan karakter arsitektur yang berbeda (untuk mewakili jamannya) namun perbedaan ini diarahkan untuk tetap bersenyawa dan mampu memperkuat eksistensi bangunan lama.Untuk itu arahan tindakan yang sesuai adalah menggunakan penyelesaian arsitektur vernakular.

c. Ruang terbuka :

Ruang terbuka yang saat ini relatif kurang tertata dan komplek cenderung pejal oleh bangunanbangunan, dengan penataan baru diharapkan dapat lebih dihasilkan tata ruang luar yang lebih baik. Ruang luar dipusatkan pada bagian tengah di sekitar kapel, dengan demikian ruang terbuka ini akan mejadi ruang luar bagi seluruh kelompok kegiatan dan akan mampu memperkuat eksistensi bangunanbangunan yang ada.

d. Struktural :

Karena konstruksi yang secara umum masih dalam kondisi baik, maka perlakuan konservasi lebih pada penguatan-penguatan struktur. Hal ini akan banyak dilakukan pada bagian selasar dan lantailantai ruang kelas di lantai atas.

e. Bangunan baru :

Bangunan baru yang dapat dideteksi saat ini akan atau sedang dibangun mencakup bangunan aula, menara dan fasilitas olah raga (lapangan basket). Disarankan sifatnya efisien dan tepat fungsi sehingga keterbatasan lahan dapat diakomodasi.Dan tampilan bangunannya dapat bersenyawa dengan bangunan konservasi yang ada namun masih dapat dikenali sesuai jamannya.

\section{Daftar Pustaka}

Ashurst, John, 2007, Conservation of ruin, ButterworthHeinemann, Oxford

Burns, John A and The Staff of HABS/HAER National Park Service U.S. Department of

The Interior, 1989, Recording historic building survey, Historic American engineering record, The American Institute of Architect Press, Washington, DC
Feilden, Bernard M, 1994, Conservation of historic building, New ed. Butterworth-Heinemann, Oxford

Forsyth, Michael (ed), 2007, Understanding historic building conservation, Blackwell Publishing Ltd, Oxford, UK

Jokilehto, Jukka, 2002, A history of architectural conservation, reprinted, Butterworth-Heinemann, Oxford

Larkham, Peter J, 1996,Conservation and the city, Routledge, London

Silverman, Helaine and D. Fairchild Ruggles, 2007, Cultural heritage and humanright, Springer Science + Business, LLC, New Yotk

The Aga Khan Trust for Culture, 1999, Conservation planning in The Aslam Mosque

neighbourhood, Darb al-Ahmar Community Development Co. A Subsidiary of Aga Khan Cultural Service-Egypt 